\title{
Morphological Traits Defining Breeding Criteria for Coastal Quinoa in Chile
}

\author{
Daniela MADRID ${ }^{1}$, Eduardo SALGADO ${ }^{1}$, Gabriela VERDUGO ${ }^{1}$, \\ Pablo OLGUÍN ${ }^{2}$, Dimitrios BILALIS ${ }^{3}$, Francisco FUENTES ${ }^{4 *}$ \\ 'Pontificia Universidad Católica de Valparaíso, Facultad de Agronomia, Casilla 4D, Quillota, \\ Chile;.madrid.toro@gmail.com; esalgado@ucv.cl; gabriela.verdugo@ucv.cl \\ ${ }^{2}$ Pontificia Universidad Católica de Valparaíso, Instituto de Geografia, Avenida Brasil 2241, Valparaíso, Chile; pablo.olguin@pucv.cl \\ ${ }^{3}$ Agricultural University of Athens, School of Agriculture, Engineering and Environmental Sciences, Department of Crop Science, Laboratory of \\ Agronomy, 75 Iera Odos str., 11855 Athens, Greece; bilalisdimitrios@gmail.com \\ ${ }^{4}$ Pontificia Universidad Católica de Chile, Facultad de Agronomía e Ingenieria Forestal, Av. Vicuña Mackenna 4860, Macul. Casilla 306-22, \\ Santiago,Chile;frfuentesc@uc.cl (*orrespondingauthor)
}

\begin{abstract}
Coastal/lowland quinoa ecotype is an important source of germplasm due to its cultivation in cold-temperate and high latitude areas. However, the interaction of its morphological traits and yields to define breeding criteria is unknown. The present study was designed to characterize the phenotypic diversity of twelve coastal/lowland quinoas using sixteen standardized morphological descriptors under rainfed conditions in central Chile. Complementary analysis of uni- and multivariate tools allowed a fuller understanding of interrelationships within quinoa germplasm. Through the analysis of frequency distribution, it was possible to determine that genotypes were characterized by plants having low height and medium grain yield. Cluster analysis revealed that plant morphological variables were independently grouped from grain yield components. Additionally, principal component analysis (PCA, $74.8 \%$ of total variation data), revealed the existence of three outstanding genotypes (QC01, QC02 and QC05) that were distantly located from the average dispersion of entire germplasm collection. These genotypes were associated with grain yield components, allowing the identification of two groups of high yield (VI and VII), which yielded 3337.7 and $3052.0 \mathrm{~kg} \mathrm{ha}^{-1}$, respectively. The data set presented in this study is the first report of coastal/lowland quinoas assessed in central Chile and could assist the development of breeding programmes in cold-temperate areas having similar agro-climatic conditions.
\end{abstract}

Keywords: Chenopodium quinoa, grain yield, landrace, multivariate analysis, rainfed

\section{Introduction}

Quinoa (Chenopodium quinoa Willd.) is a grain crop that is cultivated in the Andes region ranging from central valleys of Colombia to the southern zone of Chile. Its expansion through different geographical areas of Latin America has been possible due to ancestral peasant practices of domestication, use and seed exchange among Andean farmers (Fuentes, 2008). These practices have conserved a high phenotypic variability which allows its adaptation to different ecological environments, such as relative humidities from $40 \%$ to $80 \%$, altitude ranges from sea level to 4,000 m.a.s.l. and a wide range of temperatures ranging from 8 to $38^{\circ} \mathrm{C}$ (Bazile et al., 2013).
According to the adaptability of quinoa to the different geographical contexts of the Andean region, five ecotypes have been described, which differ in phenology, morphology, adaptation to biotic and abiotic factors and its use. These ecotypes correspond to (i) Inter Andean valleys quinoa (in Colombia, Ecuador, and Peru); (ii) Highlands quinoa (in Peru and Bolivia); (iii) Yungas quinoa (in Bolivian subtropical forest); (iv) Salares quinoa in salt flats (in Bolivia, northern Chile, and Argentina); and (v) Coastal quinoa, from lowlands or sea level (in central and southern Chile) (Risi and Galway 1984; Fuentes et al., 2012). The expansion routes from the Titicaca Lake have been supported with genetic data as revealed with the use of molecular markers and genomic resources of the quinoa genome (Fuentes et al., 2009, 2012; Jarvis et al., 2017). 
The coastal ecotype is found along the south-central zone of Chile between the rainfed area of O'Higgins region and the rainy area of Araucanía and Los Lagos regions (Fuentes et al., 2009; Sosa-Zuniga et al., 2017). Quinoas from rainfed area respond to specific characteristics of their environment, including adaptation to saline and sandy soils, as well as to average annual precipitation of 500 to $650 \mathrm{~mm}$ distributed during autumn and winter months, while in the southern zone quinoa grows in a pre-mountain area with more than 2,000 $\mathrm{mm}$ of annual precipitation distributed evenly throughout the year (Bazile et al., 2014). The plants are typically medium in size and minimally branched, panicles are glomerular, intermediate and amarantiform, grains varying from 1.7 to $2.2 \mathrm{~mm}$ in diameter and maturity period ranging from 150 to 190 days (Miranda et al., 2012; 2013; Zurita-Silva et al., 2014).

In the rainfed area, quinoa seed conservation is carried out by farmers who have maintained the seeds for generations, developing their own individual seed selection criteria according to their preferences (Fuentes et al., 2012). In the past, quinoa was cultivated in small scale farming systems and consumed by the farm dwellers themselves with traditional practices characterized by low-external-input farm management. In this scenario, there was no priority to improve the seeds, since it was only a marginal crop within the family farms. Even though the traditional system of production persist, the scale of production has changed, thus not only the family gardens are still cultivated but larger scale of production is utilized in rotation with other crops in order to increase the income per hectare (Olguín, 2011). Nevertheless, there is no documentation regarding agro morphological traits variation of coastal quinoas for preliminary identification of local varieties with stable yields to improve quinoa productivity on-farm. The goals of the present study were to characterize the morphological diversity of twelve quinoa genotypes and to identify outstanding genotypes for quinoa production under rainfed conditions in central area of Chile.

\section{Materials and Methods}

\section{Description of the study site}

The study was carried out in a field located in the Marchigie locality, belonging to the rainfed area of O'Higgins region in Chile, during the 2014-2015 season (34 $17^{\prime} 9^{\prime}$ 'S and $71^{\circ} 46^{\prime} 5^{\prime}$ 'S altitude: $205 \mathrm{~m}$ ). The area is characterized by a warm temperate climate with a prolonged dry season, with temperatures reaching up to $29.5^{\circ} \mathrm{C}$ (Table $1)$. The soil was classified as having a sandy loam texture, with a $\mathrm{pH}$ of 5.44; an electrical conductivity of $0.09 \mathrm{mS} \mathrm{cm}^{-1}$ and organic matter content of $3.25 \%$ (Table 2). The plot size of the experiment was $252 \mathrm{~m}^{2}$, in which each accession was established as a plot of three $3.5 \mathrm{~m}$ rows with $0.5 \mathrm{~m}$ between rows and $0.5 \mathrm{~m}$ between plants.

\section{Biological material}

Twelve local genotypes were used for morphological characterization (Table 3). Four accessions where collected at Paredones, two at Pumanque and six at Pichilemu cities, which have been kept in the active seed bank at Pontifical Catholic University of Chile.

\section{Protocol for collecting data}

Sixteen morphological descriptors were studied that were grouped as follows: (i) discrete variables: $\mathrm{GH}$, growth habit; MSS, main stem shape; MSC, main stem colour; $\mathrm{NPB}$, number of primary braches; PCPS, panicle colour at physiological stage; PS, panicle shape; PD, panicle density; PC, pericarp colour; EC, episperm colour; (ii) continuous variables: $\mathrm{PH}$, plant height; $\mathrm{StD}$, stem diameter; PL, panicle length; PW, panicle width; SeD, seed diameter; 1000SW, 1000 seed weight; and GY, grain yield, as defined by Biodiversity (2013).

\section{Statistical procedures}

The analysis of the data considered the analysis of variance based on a completely random block design with 12 genotypes and 3 replicates. Treatment averages at Marchigüe locality were separated using the Tukey test $(\alpha=$ $0.05)$. Parametric and non-parametric analysis of the data was performed using the INFOSTAT (InfoStat, 2014) statistical software. Multivariate analysis was performed using the following methods: (i) the total correlation between variables using the Pearson coefficient complement (Clifford and Stephenson 1975); (ii) principal component analysis (PCA) (Hair et al., 1992) and (iii) cluster analysis. A dendogram was constructed using the complement of the Pearson coefficient and the algorithm for UPGMA (unweighted pair-group method using an arithmetic average) as described by Sokal and Michener (1958).

\section{Results}

\section{Frequency distribution of variables}

According to the morphological descriptors used in the study, nine of these corresponded to the description of discrete variables. These were: GH, growth habit; MSS, main stem shape; MSC, main stem colour; NPB, number of primary braches; PCPS, panicle colour at physiological stage; PS, panicle shape; PD, panicle density; PC, pericarp colour; EC, episperm colour. Table 4 shows the average distribution of each descriptor in the 12 genotypes evaluated in Marchigüe locality. The GH descriptor genotypes were classified into the "simple" category with $92 \%$ of accessions, meanwhile the "branched to $2 / 3$ " of plant category was represented by only one. All the genotypes evaluated for the MSS descriptor corresponded to the "angular" category. The main colour for the MSC descriptor was "yellow" (92\%) and secondary, pink (8\%). For the NPB descriptor the genotypes were concentrated in the category "without branches" with $92 \%$ of accessions and with "3 branches" only $8 \%$. The PCPS descriptor considered $50 \%$ of genotypes into the "yellow" category and $50 \%$ into the "brown" one. For the PS descriptor, most of genotypes were classified into the "intermediate" category (92\%), and for PD descriptor most had "intermediate" (92\%) panicles. The PC descriptor presented a distribution into three categories, $42 \%$ was light coffee, $25 \%$ dark coffee and $8 \%$ yellow. Finally, for the EC descriptor $75 \%$ of the genotypes were classified as cream colour and $25 \%$ as white.

The frequency distribution of seven continuous descriptors is shown in Table 4. The $\mathrm{PH}$ descriptor was 
192

Table 1. Mean and ranges of monthly maximum and minimum temperatures and relative humidity recorded at Marchigüe locality ${ }^{*}$

\begin{tabular}{cccc}
\hline Month & $\begin{array}{c}\text { Maximum }\left({ }^{\circ} \mathrm{C}\right) \\
(\text { range })\end{array}$ & $\begin{array}{c}\text { Minimum }\left({ }^{\circ} \mathrm{C}\right) \\
(\text { range })\end{array}$ & $\begin{array}{c}\mathrm{RH}(\%) \\
(\text { range })\end{array}$ \\
\hline November & $23.8(15.8-29.6)$ & $6.9(1.4-10.7)$ & $58.5(32-89)$ \\
December & $24.9(16.3-30.8)$ & $7.3(1.2-11.9)$ & $61(29-97)$ \\
January & $28.4(19.7-34)$ & $8.2(3.7-13.6)$ & $59.2(29-95)$ \\
\hline February & $29.5(24.9-35.3)$ & $6.5(1.9-9.6)$ & $70.5(51-92)$ \\
March & $28.9(23.4-36.8)$ & $8.9(2.7-15.2)$ & $57.5(43-92)$ \\
\hline${ }^{*}$ Data set recorded during 2014-2015 & & &
\end{tabular}

Table 2. General soil characterization of experimental plots at Marchigüe locality $(0-20 \mathrm{~cm})^{*}$

\begin{tabular}{|c|c|c|c|}
\hline Soil parameters & Unit & Normal ranges & Marchigüe \\
\hline \multicolumn{4}{|c|}{ Chemical properties } \\
\hline $\mathrm{pH}$ suspension & - & - & 5.44 \\
\hline CE suspension & $\mathrm{mS} \mathrm{cm}^{-1}$ & $<0.5$ & 0.09 \\
\hline M.O & $\%$ & - & 3.25 \\
\hline \multicolumn{4}{|l|}{ Available } \\
\hline $\mathrm{N}$ & $\mathrm{mg} \mathrm{kg}^{-1}$ & * & 44 \\
\hline P Olsen & $\mathrm{mg} \mathrm{kg}^{-1}$ & $20-40$ & 6 \\
\hline K & $\mathrm{mg} \mathrm{kg}^{-1}$ & $150-300$ & 116 \\
\hline $\mathrm{Cu}$ & $\mathrm{mg} \mathrm{kg}^{-1}$ & $0.6-11$ & 1.3 \\
\hline $\mathrm{Fe}$ & $\mathrm{mg} \mathrm{kg}^{-1}$ & $>4.5$ & 170 \\
\hline $\mathrm{Mn}$ & $\mathrm{mg} \mathrm{kg}^{-1}$ & $>1.0$ & 17.7 \\
\hline $\mathrm{Zn}$ & $\mathrm{mg} \mathrm{kg}^{-1}$ & $>1.0$ & 1.3 \\
\hline $\mathrm{B}$ & $\mathrm{mg} \mathrm{kg}^{-1}$ & $1.0-1.5$ & 0.1 \\
\hline S & $\mathrm{mg} \mathrm{kg}^{-1}$ & $>9$ & 2 \\
\hline \multicolumn{4}{|c|}{ Interchangeable } \\
\hline $\mathrm{Ca}$ & meq $100 \mathrm{gr}^{-1}$ & $>4.1$ & 3.2 \\
\hline $\mathrm{Mg}$ & meq $100 \mathrm{gr}^{-1}$ & $>0.5$ & 1.2 \\
\hline K & meq $100 \mathrm{gr}^{-1}$ & $>0.38$ & 0.3 \\
\hline $\mathrm{Na}$ & meq $100 \mathrm{gr}^{-1}$ & $<0.5$ & 0.1 \\
\hline $\mathrm{CEC}^{*}$ & meq $100 \mathrm{gr}^{-1}$ & - & 7 \\
\hline \multicolumn{4}{|l|}{ Physical } \\
\hline Clay & $\%$ & - & 13.3 \\
\hline Silt & $\%$ & - & 24 \\
\hline Sand & $\%$ & - & 62.7 \\
\hline Texture class & & & Sandy loam \\
\hline
\end{tabular}

${ }^{*}$ CEC: cation exchange capacity

Table 3. Detail of quinoa genotypes used in the study*

\begin{tabular}{cccccc}
\hline Genotype & Accession ID & Place name & Latitude & Longitude & Altitude (m) \\
\hline QC01 & QPU001 & Centro Pumanque & $34^{\circ} 36^{\prime} 11.66^{\prime \prime} \mathrm{S}$ & $71^{\circ} 39^{\prime} 11.88^{\prime \prime} \mathrm{W}$ & 120 \\
QC02 & QPU002 & Centro Pumanque & $34^{\circ} 44^{\prime} 7.45^{\prime \prime} \mathrm{S}$ & $71^{\circ} 39^{\prime} 55.54^{\prime \prime} \mathrm{W}$ & 122 \\
QC03 & QPA001 & La Quesería & $34^{\circ} 38^{\prime} 58.14^{\prime \prime} \mathrm{S}$ & $71^{\circ} 52^{\prime} 8.26^{\prime \prime} \mathrm{W}$ & 66 \\
QC04 & QPA002 & Paredones Centro & $34^{\circ} 38^{\prime} 47.35^{\prime \prime} \mathrm{S}$ & $71^{\circ} 53^{\prime} 58.50^{\prime \prime} \mathrm{W}$ & 56 \\
QC05 & QPA003 & El Peral & $34^{\circ} 29^{\prime} 49.42^{\prime \prime} \mathrm{S}$ & $71^{\circ} 59^{\prime} 49.58^{\prime \prime} \mathrm{W}$ & 10 \\
QC06 & QPA004 & La Vega & $34^{\circ} 35^{\prime} 33.52^{\prime \prime} \mathrm{S}$ & $71^{\circ} 50^{\prime} 48.86^{\prime \prime} \mathrm{W}$ & 48 \\
QC07 & QPI001 & La Palmilla & $34^{\circ} 32^{\prime} 9.6^{\prime \prime S}$ & $71^{\circ} 57^{\prime} 49.69^{\prime \prime} \mathrm{W}$ & 24 \\
QC08 & QPI002 & Rodelillo & $34^{\circ} 31^{\prime} 1.42^{\prime \prime} \mathrm{S}$ & $71^{\circ} 56^{\prime} 37.63^{\prime \prime} \mathrm{W}$ & 95 \\
QC09 & QPI003 & La Plaza & $34^{\circ} 32^{\prime} 9.66^{\prime \prime S}$ & $71^{\circ} 59^{\prime} 15.16^{\prime \prime} \mathrm{W}$ & 15 \\
QC10 & QPI004 & La Plaza & $34^{\circ} 33^{\prime} 2.76^{\prime \prime} \mathrm{S}$ & $71^{\circ} 59^{\prime} 22.78^{\prime \prime} \mathrm{W}$ & 17 \\
QC11 & QPI005 & La Palmilla & $34^{\circ} 34^{\prime} 8.66^{\prime \prime S}$ & $71^{\circ} 55^{\prime} 50.97^{\prime \prime} \mathrm{W}$ & 27 \\
QC12 & QPI006 & Cáhuil & $34^{\circ} 18^{\prime} 8.65^{\prime \prime} \mathrm{S}$ & $71^{\circ} 48^{\prime} 53.37^{\prime \prime} \mathrm{W}$ & 12 \\
\hline
\end{tabular}

${ }^{\bar{*}}$ Genotypes collected are registered in the active seed bank of Pontifical Catholic University of Chile 
classified in a range that describes in general medium and short plants, with $58 \%$ of genotypes into the short category $(<113 \mathrm{~cm})$ and $33 \%$ into the medium $(113$ to $139 \mathrm{~cm})$. However, only one genotype was classified into the tall plants category $(>139 \mathrm{~cm})$. The $\mathrm{StD}$ descriptor classified most of collection as small (83\%), meanwhile medium and large diameter were found only for one genotype, respectively. For the descriptor PL, the genotypes were classified as short (50\%) and medium length (42\%). The genotype collection was characterized for the PW descriptor as small, with $92 \%$ into the range of 11.9 to $22.7 \mathrm{~cm}$. The
$\mathrm{SeD}$ descriptor was considered medium for $50 \%$ of genotype collection in a range of 1.7 to $2.0 \mathrm{~mm}$, meanwhile $17 \%$ and $33 \%$ of genotypes were small (1.4 to 1.7) and big (2.0 to 2.3), respectively. The 1000SW descriptor was classified as medium ( 3.4 to $3.8 \mathrm{mg}$ ) for $50 \%$ of collection and lower $(<3.4 \mathrm{mg})$ and higher $(>3.8 \mathrm{mg})$ for $33 \%$ and $17 \%$ of genotypes, respectively. The GY descriptor was concentrated in the range of low yields with $58 \%$ of collection between 630 to $1,613 \mathrm{~kg} \mathrm{ha}^{-1}$, meanwhile $17 \%$ and $25 \%$ of genotypes were into the medium $\left(1,613\right.$ to $\left.2,596 \mathrm{~kg} \mathrm{ha}^{-1}\right)$ and high yields (2,596 to $\left.3,579 \mathrm{~kg} \mathrm{ha}^{-1}\right)$ ranges, respectively.

Table 4. Frequency distribution of discrete and continuous variables of morphological traits of quinoa genotypes evaluated under rainfed conditions at Marchigüe locality*

\begin{tabular}{|c|c|c|c|c|}
\hline \multirow{2}{*}{ Variables } & \multirow{2}{*}{ Plant traits } & \multirow{2}{*}{ Category } & \multicolumn{2}{|c|}{ Frequency } \\
\hline & & & Absolute & Relative (\%) \\
\hline \multirow{19}{*}{ Discrete variables } & \multirow{2}{*}{$\mathrm{GH}$} & Simple & 11 & 92 \\
\hline & & Branched to $2 / 3$ & 1 & 8 \\
\hline & \multirow{2}{*}{ MSS } & Angular & 12 & 100 \\
\hline & & Cylindrical & 0 & 0 \\
\hline & \multirow{2}{*}{ MSC } & Yellow & 11 & 92 \\
\hline & & Pink & 1 & 8 \\
\hline & \multirow{2}{*}{ NPB } & 0 & 11 & 92 \\
\hline & & 3 & 1 & 8 \\
\hline & \multirow{2}{*}{ PCPS } & Yellow & 6 & 50 \\
\hline & & Brown & 6 & 50 \\
\hline & \multirow{2}{*}{ PS } & Glomerulate & 1 & 8 \\
\hline & & Intermediate & 11 & 92 \\
\hline & \multirow{2}{*}{$\mathrm{PD}$} & Compact & 1 & 8 \\
\hline & & Intermediate & 11 & 92 \\
\hline & \multirow{3}{*}{ PC } & Dark coffee & 6 & 25 \\
\hline & & Light coffee & 5 & 42 \\
\hline & & Yellow & 1 & 8 \\
\hline & \multirow{2}{*}{ EC } & Cream & 9 & 75 \\
\hline & & White & 3 & 25 \\
\hline \multirow{21}{*}{ Continuous variables } & \multirow{3}{*}{$\mathrm{PH}(\mathrm{cm})$} & $86.98-113.33$ & 7 & 58 \\
\hline & & $113.33-139.68$ & 4 & 33 \\
\hline & & $139.68-166.04$ & 1 & 8 \\
\hline & \multirow{3}{*}{$\mathrm{StD}(\mathrm{cm})$} & $1.26-1.54$ & 10 & 83 \\
\hline & & $1.54-1.83$ & 1 & 8 \\
\hline & & $1.83-2.11$ & 1 & 8 \\
\hline & \multirow{3}{*}{$\mathrm{PL}(\mathrm{cm})$} & $16.09-32.47$ & 6 & 50 \\
\hline & & $32.47-48.86$ & 5 & 42 \\
\hline & & $48.86-65.24$ & 1 & 8 \\
\hline & \multirow{3}{*}{ PW $(\mathrm{cm})$} & $11.90-22.77$ & 11 & 92 \\
\hline & & $22.77-33.63$ & 0 & 0 \\
\hline & & $33.63-44.50$ & 1 & 8 \\
\hline & \multirow{3}{*}{$\mathrm{SeD}(\mathrm{mm})$} & $1.43-1.73$ & 2 & 17 \\
\hline & & $1.73-2.03$ & 6 & 50 \\
\hline & & $2.03-2.33$ & 4 & 33 \\
\hline & \multirow{3}{*}{$1000 \mathrm{SW}(\mathrm{mg})$} & $3.03-3.41$ & 4 & 33 \\
\hline & & $3.41-3.79$ & 6 & 50 \\
\hline & & $3.79-4.17$ & 2 & 17 \\
\hline & \multirow{3}{*}{ GY $\left(\mathrm{kg} \mathrm{ha}^{-1}\right)$} & $630.80-1613.60$ & 7 & 58 \\
\hline & & $1613.61-2596.40$ & 2 & 17 \\
\hline & & $2596.41-3579.20$ & 3 & 25 \\
\hline
\end{tabular}

${ }^{*} \mathrm{GH}$, growth habit; MSS, main stem shape; MSC, main stem colour; NPB, number of primary braches; PCPS, panicle colour at physiological stage; PS, panicle shape; PD, panicle density; PC, pericarp colour; EC, episperm colour; PH, plant height; StD, stem diameter; PL, panicle length; PW, panicle width; SeD, seed diameter; $1000 S W, 1000$ seed weight; GY, grain yield 
194

\section{Correlation among variables}

Pearson coefficient correlation among continuous variables of quinoa genotypes is shown in Table 5. Highest correlation was found between PW - StD $(\mathrm{R}=0.82), \mathrm{PW}$ PL $(\mathrm{R}=0.79)$, PW - PH $(\mathrm{R}=0.73)$. Other significant correlations were $\mathrm{StD}$ - $\mathrm{PH}(\mathrm{R}=0.68), \mathrm{PL}-\mathrm{PH}(\mathrm{R}=0.68)$ and PL - StD $(\mathrm{R}=0.58)$.

\section{Principal component analysis}

The principal component analysis shown in Fig. 1 revealed that the first two major components of the analysis accounted for $74.8 \%$ of the total qualitative variation of data, which were selected for further analysis following the criteria described by Kaiser (1960). In the figure, the genotypes QC01, QC02 and QC05 were distantly located from those associated at central point of biplot. The genotype QC05 was located at the right zone of quadrant (positive values in the PC1) and presented a positive correlation (acute angle) with seed traits (GY, PL and PW), meanwhile genotypes QC01 and QC02 were located in the right zone of quadrant, having a positive correlation with $1000 \mathrm{SW}$ and PW descriptors, respectively. The rest of genotypes were located at the left zone of quadrant, revealing less correlation with seed traits.

\section{Cluster analysis}

The dendogram shown in Fig. 2, revealed the presence of two different groups among the descriptors. The first group was represented for the seed descriptors ( $\mathrm{SeD}$, $1000 \mathrm{SW}$ and GY) and the second group for variables that determined plant morphology (PL, PW, StD and PH).

A correlation matrix involving the complement of the Pearson coefficient was used to construct a dendrogram using the UPGMA algorithm. The genotypes were grouped into seven groups (Fig. 3). Group I had one genotype and was represented by a tall plant with medium yield. Group II

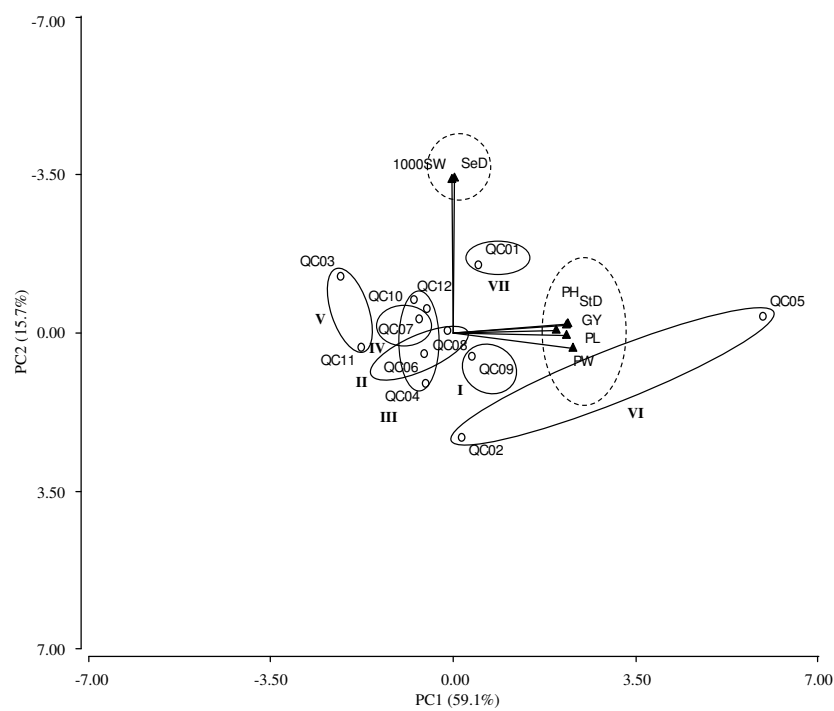

Fig. 1. Principal component analysis (PCA) biplot of twelve quinoa genotypes (white circle) and seven morphological traits (black triangle) evaluated under rainfed conditions at Marchigüe locality. PH, plant height; StD, stem diameter; PL, panicle length; PW, panicle width; SeD, seed diameter; 1000SW, 1000 seed weight; GY, grain yield consisted of two genotypes characterized by having short plants with medium yields. Group III was represented by three genotypes having medium height and yields. Group IV was composed of one genotype, which was characterized by a short plant with low yield, despite the fact that it had large panicles. Group V was represented by two genotypes that had short plants with low yields. Group VI consisted of two genotypes that had tall plants and high yields. Finally Group VII was represented by one genotype with medium height and high yield.

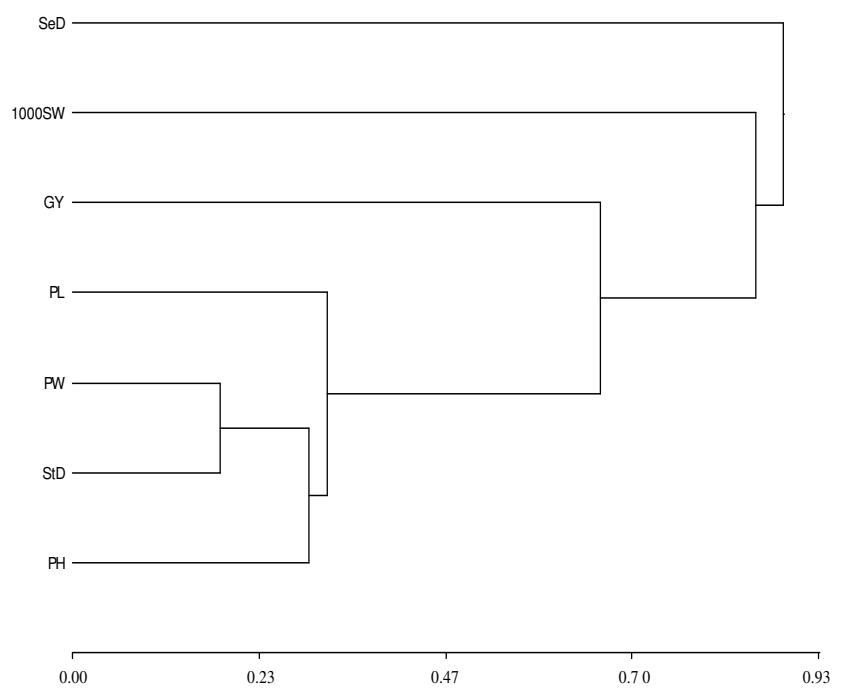

Fig. 2. Dendogram showing distances between 7 quantitative variables of 12 quinoa genotypes evaluated under rainfed conditions at Marchigüe locality. $\mathrm{PH}$, plant height; $\mathrm{StD}$, stem diameter; PL, panicle length; PW, panicle width; SeD, seed diameter; 1000SW, 1000 seed weight; GY, grain yield

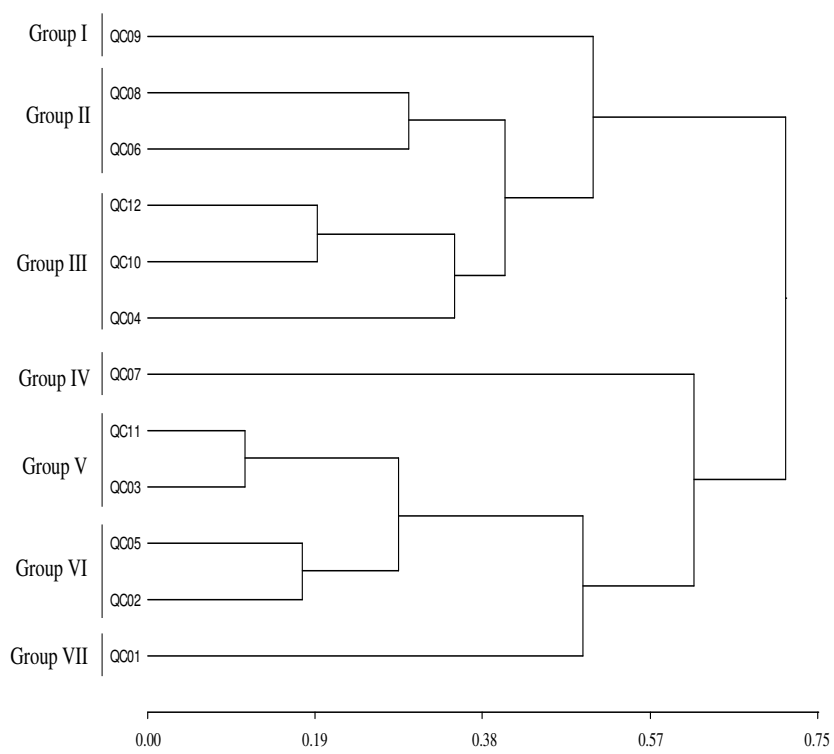

Fig. 3. Cluster analysis for characterization of 12 quinoa genotypes grown under rainfed conditions at Marchigüe locality 


\section{Discussion}

The data set provided a general definition of coastal quinoa genotypes growing under Mediterranean-type climate, which express medium to small growth pattern. This definition is supported by positive correlations found among PW - PH, PW - PL and PW - PH descriptors (Table 5). Likewise, the cluster analysis (Fig, 2) also correlated with this definition, showing that PW descriptor was associated with a $\mathrm{StD}, \mathrm{PH}$ and PL. These positive associations confirm the pattern observed in the field, consisting of tall plants with large panicles and thick stems.

Risi and Galwey (1989) assessing Peruvian germplasm described a large amount of variation for $\mathrm{StD}$ (range $=0.7-$ $5.5 \mathrm{~cm}$; mean $=2.27 \mathrm{~cm})$ and $\mathrm{PH}($ range $=0.36-2.56 \mathrm{~m}$; mean $=1.58)$. In contrast, Rojas $(2003)$ reported that morphological descriptors for Bolivian germplasm had a narrow variation for $\mathrm{StD}$, ranging from 1.02 to $2.63 \mathrm{~cm}$ $($ mean $=1.71 \mathrm{~cm})$ and for $\mathrm{PH}$ from 0.54 to $1.74 \mathrm{~m}($ mean $=$ $1.11 \mathrm{~m})$. Similarly, Chilean germplasm (Salar ecotype) assessed by Fuentes \& Bhargava (2011) showed a narrow variation for the $\mathrm{StD}$ variable, ranging from 0.88 to $1.94 \mathrm{~cm}$ and for $\mathrm{PH}$ from 1.01 to $1.91 \mathrm{~m}$. A comparison of data presented in this study with the abovementioned reports confirms in general that phenotypic behaviour of coastal quinoa in central area of Chile does not show particularly extreme values for any of the variables measured.

The principal component analysis showed that three accessions were distantly located from those associated at central point of biplot (QC01, QC02 and QC05). In addition, the cluster analysis among descriptors revealed two main associations, the first related to plant morphology and the second to characteristics of grain (Fig. 2). The combined multivariate analysis of data also revealed outstanding genotypes, such as QC01 which was mainly associated with 1000 SW and SeD descriptors, QC02 with PW and QC05 is associated with GY. Furthermore, these genotypes were related and classified in group VI (QC05 and QC02 genotypes) and group VII (QC01) (Fig. 1 and 3). The association of major groups of variable-traits has been similarly described in Chilean quinoa germplasm (Salar ecotype) through leaf, grain yield and plant/inflorescence characteristics (Fuentes \& Bhargava, 2011). Likewise, Franco and Hidalgo (2003) have reported in Bolivian quinoa germplasm that plant structure variables were significantly correlated with variables such as precocity (dates of mid bloom and physiological ripeness), confirming that variation in precocity influences plant shape directly, and that it is possible to combine the range variables of grain traits (e.g. harvest index) with plant phenology and plant architecture independently in one genotype.

The general classification of germplasm mediated by cluster analysis revealed that groups VI and VII had the highest grain yield, with 3,338 and $3,052 \mathrm{~kg} \mathrm{ha}^{-1}$ respectively. In contrast, groups IV and V had the lowest yields with 919.7 and $945.6 \mathrm{~kg} \mathrm{ha}^{-1}$, respectively. The wide variation observed in yields suggests a great opportunity to develop plant breeding strategies to support quinoa cultivation in rainfed areas in Chile and similar Mediterranean-type climate conditions. Similarly, the clusters analysis revealed that group VI was characterized having tall plants, large panicles and tick stems.

Interestingly, the accession QC09, belonging to group I presented similar plant height to accessions in group VI, however the grain yield of group I represented $50 \%$ of yield obtained in group VI, confirming that there is no correlation between plant size and grain yield, as previously reported by Fuentes \& Bhargava (2011), using "Salar" genotypes grown under lowland desert conditions. Likewise, group VII (accession QC01) presented the highest values for $\mathrm{SeD}$ and $1000 \mathrm{SW}$ in the entire collection, however these grain characteristics did not correlate with higher yields due to presenting smaller panicles (PL and PW descriptor) than accessions in group VI.

Table 5. Pearson coefficient of correlation among morphological variables of quinoa accessions evaluated under rainfed conditions at Marchigüe locality*

\begin{tabular}{|c|c|c|c|c|c|c|c|}
\hline Trait & $\mathrm{PH}$ & $\mathrm{StD}$ & PL & PW & $\mathrm{SeD}$ & $1000 S W$ & GY \\
\hline $\mathrm{PH}$ & 1 & & & & & & \\
\hline $\mathrm{StD}$ & 0.68 & 1 & & & & & \\
\hline PL & 0.68 & 0.58 & 1 & & & & \\
\hline PW & 0.73 & 0.82 & 0.79 & 1 & & & \\
\hline $\mathrm{SeD}$ & 0.13 & 0.22 & 0.17 & -0.0015 & 1 & & \\
\hline $1000 S W$ & -0.13 & -0.21 & -0.19 & -0.1 & -0.04 & 1 & \\
\hline GY & 0.35 & 0.26 & 0.43 & 0.32 & -0.11 & 0.1 & 1 \\
\hline
\end{tabular}

*Values in bold represent significant correlations $(\mathrm{P} \leq 0.05)$. PH, plant height; StD, stem diameter; PL, panicle length; PW, panicle width; SeD, seed diameter; $1000 \mathrm{SW}$, 1000 seed weight; GY, grain yield

Table 6. Descriptive variables for seven groups classified by cluster analysis in quinoa genotypes evaluated under rainfed conditions at Marchigüe locality*

\begin{tabular}{|c|c|c|c|c|c|c|c|c|c|c|c|c|c|c|}
\hline \multirow{2}{*}{ Descriptor } & \multicolumn{14}{|c|}{ Group } \\
\hline & I & & II & & III & & IV & & $\overline{\mathrm{V}}$ & & VI & & $\overline{\mathrm{VI}}$ & \\
\hline PH & 134.38 & $a b$ & 109.89 & $\mathrm{bc}$ & 115.71 & $\mathrm{ab}$ & 112.34 & bc & 90.02 & c & 141.29 & $\mathrm{a}$ & 115.47 & $a b c$ \\
\hline $\mathrm{StD}$ & 1.54 & $a b$ & 1.35 & b & 1.31 & b & 1.35 & b & 1.35 & b & 1.86 & a & 1.43 & b \\
\hline PL & 28.36 & $\mathrm{~b}$ & 33.06 & $a b$ & 30.93 & b & 34.24 & $a b$ & 18.05 & b & 48.83 & $\mathrm{a}$ & 32.79 & $\mathrm{ab}$ \\
\hline PW & 17.18 & $\mathrm{~b}$ & 16.02 & b & 15.59 & b & 16.55 & $\mathrm{~b}$ & 12.1 & $\mathrm{~b}$ & 34.2 & a & 15.77 & $\mathrm{~b}$ \\
\hline $\mathrm{SeD}$ & 2.00 & $a b$ & 1.95 & $\mathrm{ab}$ & 1.84 & b & 2.14 & $a b$ & 2.07 & $a b$ & 1.76 & b & 2.33 & a \\
\hline $1000 S W$ & 3.20 & a & 3.45 & a & 3.72 & a & 3.44 & a & 3.62 & a & 3.52 & a & 3.73 & a \\
\hline GY & 1584.27 & b & 1904.27 & b & 1406.44 & b & 919.7 & $\mathrm{~b}$ & 945.6 & b & 3337.7 & a & 3052.0 & $\mathrm{a}$ \\
\hline
\end{tabular}


196

\section{Conclusions}

The accessions that presented the highest yields in the entire collection were QC02 and QC05. The frequency distribution of variables allowed a general classification of quinoa accessions, which was represented by plants having low height and medium grain yield. Cluster analysis was an efficient method for germplasm classification based on yield and morphological characteristics. This approach allowed us to classify the entire collection into seven groups, identifying group VI and VII as the most outstanding in relation to productive performance. Additionally, the classification contributed to identify significant correlations between different quinoa descriptors, emphasizing the relationships between PW and StD, and between PW and PL. The use of multivariate approaches also confirmed the relationship among variables into two main groups, containing plant architecture descriptors and grain characteristics, respectively.

The data set presented in this study is the first report of quinoa assessed under rainfed conditions of central Chile, allowing the identification of promising genetic lines to generate future varieties. This research will be a great help in the development of new plant breeding programmes for quinoa in marginal areas having similar Mediterranean-type climate.

\section{Acknowledgements}

We thank all the QuinoaLab UC members for their helpful discussion and preparation of this manuscript. This work was supported by institutional funds and by FIC-IDI30135550-0, from GORE-O'Higgins and PYT-2016-0079, from FIA.

\section{References}

Bazile D, Fuentes F, Mujica A (2013). Historical perspectives and domestication. In: Bhargava Atul, Srivastava Shilpi. Quinoa: botany, production and uses. Wallingford, CABI pp 16-35.

Bazile D, Martínez EA and Fuentes F (2014). Diversity of Quinoa in a Biogeographical Island: a Review of Constraints and Potential from Arid to Temperate Regions of Chile. Notulae Botanicae Horti AgrobotaniciCluj-Napoca42(2): 289-298.

Bioversity International (2013). Descriptores para quinua (Chenopodium quinoa Willd.) y sus parientes silvestres. Bioversity International y FAO, ISBN: 978-92-9043-927-1.

Clifford HT, Stephenson W (1975). An Introduction to Numerical Classification. Academic Press, New York, New York.

Franco T, Hidalgo R (2003). Análisis estadístico de datos de caracterización morfológica de recursos filogenéticos. Boletín técnico no. 8. Instituto Internacional de Recursos Fitogenéticos (IPGRI), Cali, Colombia.

Fuentes F, Martínez EA, Hinrichsen PV, Jellen EN, Maughan PJ (2009). Assessment of genetic diversity patterns in Chilean quinoa (Chenopodium quinoa Willd.) germplasm using multiplex fluorescent microsatellite markers. Conservation Genetics 10:369-377.
Fuentes F (2008). Quinua: recursos fitogenéticos y su uso en la agricultura. Revista Agricultura del Desierto 4:82-101.

Fuentes F, Bazile D, Bhargava A, Martínez EA (2012). Implications of farmers' seed exchanges for on-farm conservation of quinoa, as revealed by its genetic diversity in Chile. Journal of Agricultural Science 150:702716.

Fuentes F, Bhargava A (2011). Morphological analysis of quinoa germplasm grown under lowland desert conditions. Journal of Agronomy and CropScience 197:124134.

Hair JF, Anderson RE, Tatham RL, Black WC (1992) Multivariate Data Analysis. Macmillan Publishing Company, New York.

InfoStat (2014). InfoStat versión 2014. Grupo InfoStat, FCA, Universidad Nacional de Córdoba, Argentina.

Jarvis DE, Ho YS, Lightfoot DJ, Schmöckel SM, Li B, Borm TJ, ... Kharbatia NM (2017). The genome of Chenopodium quinoa. Nature 542:307-312.

Kaiser HF (1960). The application of electronic computers to factor analysis. Educational and Psychological Measurement 20:141-151.

Miranda M, Vega-Gálvez A, Martínez EA, López J, Rodríguez M, Henríquez K, Fuentes F (2012). Genetic diversity and comparison of physicochemical and nutritional characteristics of six quinoa (Chenopodium quinoa Willd.) genotypes cultivated in Chile. Food Science and Technology (Ciência e Tecnologia de Alimentos) 32(4):19.

Miranda M, Vega-Gálvez A, Martínez EA, López J, Marín R, Aranda M, Fuentes $F$ (2013). Influence of contrasting environment on seed composition of two quinoa genotypes: nutritional and functional properties. Chilean Journal of Agricultural Research 73(2):108-116.

Olguín P (2011). Dinámicas espaciales de los sistemas de producción de quinua de la región del Libertador Bernardo O'Higgins de Chile con relación a los factores económicos y del medio ambiente. Thesis, Pontificia Universidad Católica de Valparaíso, Chile.

Risi J, Galway NW (1984). The Chenopodium grains of the Andes: Inca crops for modern agriculture. Advances in Applied Biology 10:145-216.

Risi J, Galwey NW (1989). The pattern of genetic diversity in the Andean grain crop quinoa (Chenopodium quinoa Willd.). II. Multivariate methods. Euphytica41:135-145.

Rojas W (2003). Multivariate analysis of genetic diversity of Bolivian quinoa germplasm. Food Reviews International 19(1-2):9-23.

Sokal RR, Michener CD (1958). A statistical methods for evaluating systematic relationships. The University of Kansas Science Bulletin 38:1409-1438.

Sosa V, Brito V, Fuentes F, Steinfort U (2017). Phenological growth stages of quinoa (Chenopodium quinoa Willd.) based on the $\mathrm{BBCH}$ scale. Annals of Applied Biology 171(1):117-124.

Zurita-Silva A, Fuentes F, Zamora P, Jacobsen SE, Schwember AR (2014). Breeding quinoa (Chenopodium quinoa Willd.): perspectives and potential. Molecular Breeding 34(1):13-30. 